\title{
Crego, Jorge. La forma del derecho y la libertad. Una crítica a la concepción de Rawls y Fuller sobre el valor del rule of law. Madrid: Marcial Pons, 2020.
}

\author{
Antonio Manuel Peña Freire \\ Departamento de Filosofía del Derecho \\ Universidad de Granada
}

Fecha de recepción 06/05/2020 I De publicación: 28/12/2020

Nadie duda seriamente de la relevancia filosófica de John Rawls. No ocurre lo mismo con Lon Fuller, hasta hace poco relativamente olvidado y al que apenas se recordaba por algunas fabulaciones ingeniosas. Sin embargo, Fuller ha vuelto a ser objeto de un interés teórico genuino y, desde hace unos años, asistimos a un revival fulleriano a propósito, fundamentalmente, de sus tesis sobre el rule of law, sus principios constitutivos y su dimensión moral. Del ámbito anglosajón, nos llegan aportaciones como las de Rundle (2012), Allan (2001), Nadler (2007), Waldron (2012) o las compiladas por Cane (2010). Fuera de ese marco, encontramos la obra editada por Witteveen y Burg (1999) y las de Porciello (2016), Aguilera (2017) o, modestamente, mi propio Legalidad y orden jurídico (Peña, 2017).

El libro ahora reseñado participa de ese revival, pero a diferencia de la mayoría de los trabajos referidos, es crítico con Fuller. Paradójicamente, esto confirma la importancia de Fuller y de su revival, porque hay quienes alcanzan relevancia por haber formulado tesis relevantes y quienes además la ven confirmada por ser objeto de críticas relevantes. Y es que igual que no tengo dudas sobre la relevancia de la filosofía del derecho de Fuller, tampoco las tengo a propósito de la importancia de las ideas que Jorge Crego presenta en su libro, con las que confronta las lecturas expansivas de Fuller con gran determinación y con un elaborado argumentario crítico, renovado respecto del original. Solo por estas razones, el libro de Crego es una lectura obligada tanto para quienes simpatizan con las tesis de Fuller como para sus críticos.

La obra versa sobre el supuesto valor moral del derecho y del rule of law fruto de su conexión con la libertad. Al respecto, Crego es claro: rechaza que el derecho pueda tener valor moral intrínseco por el simple hecho de presuponer que los sujetos sometidos a sus reglas son personas libres y no cree que exista una relación fuerte o moralmente significativa entre rule of law y libertad (p. 18). Lo único 
que el respeto a los principios del rule of law-los célebres ocho desiderata o principios de legalidad de Fuller-garantiza es el reconocimiento a la racionalidad deliberativa de los sujetos, que les permite anticipar las consecuencias de sus decisiones al momento de diseñar sus planes de vida. Sin embargo, esto no implica reconocer ninguna dimensión de la libertad mínimamente valiosa desde un punto de vista moral. El rule of law sería, por tanto, solo la manifestación institucional del reconocimiento de la capacidad deliberativa del sujeto, pero el valor moral del derecho será siempre dependiente del contenido de las normas jurídicas que lo componen y no de los rasgos formales que garantizan el gobierno de sus normas (pp. 20-21).

Rawls es quien sirve a Crego para definir qué es una concepción moralmente significativa de la libertad. La elección está sobradamente justificada a la vista de los méritos del filósofo americano y también porque existe cierta relación entre Fuller y Rawls, pues a la justice as fairness subyacen los principios de justicia que inspiran la concepción fulleriana del rule of law y porque en la concepción rawlsiana del rule of law también existe implícita, como en Fuller, una visión del hombre como persona moral libre e igual (pp. 18-20), aunque finalmente la de Rawls se demostrará mucho más ambiciosa que la presupuesta por Fuller.

Efectivamente, según Crego (p. 179), la protección que dispensan a la libertad los principios de legalidad es demasiado débil como para dar por satisfecha una concepción de la libertad como la rawlsiana. El grado de reconocimiento de la capacidad para la autoaplicación de las normas por parte del sujeto, por ejemplo, es insuficiente, porque aunque el rule of law presupone esa capacidad, lo hace en un sentido muy restringido, ya que equivale a la "traslación del trabajo necesario para plasmar la exigencias normativas del derecho en la realidad social de la autoridad al sujeto jurídico", lo que supone tratar "al sujeto como un 'autómata' y no como autónomo" (p. 180). El rule of law no genera el derecho del individuo a decidir por sí mismo qué conducta llevar a cabo conforme a su propio plan de vida, pero sí lo somete a los “designios” del orden jurídico (pp. 180-181): "si es eso lo que Fuller considera que es ser un agente responsable (...) difícilmente se puede considerar que esa cualidad del sujeto jurídico, por sí misma, lo convierte en libre". A una conclusión similar a esta llega Crego cuando analiza la significación de la capacidad para la planificación de la propia conducta que asegura el rule of law: anticipar las consecuencias de los propios actos favorece el diseño de planes de vida por los individuos conforme a su propia concepción del bien (p. 181) y, sin embargo, para Crego (p. 186), es perfectamente posible un gobierno respetuoso con el rule of law que cercene de modo dramático la facultad de los individuos para 
elaborar su propia concepción del bien, para dotarla de valor moral por haberla elegido y para perseguirla y promoverla en la vida real: alcanzar estas cotas requiere la protección de una serie de libertades básicas sustanciales, que no están comprendidas en los principios (formales) de legalidad. Una persona inserta en un rule of law goza de capacidad de previsión, pero la capacidad de elección que asegura el rule of law y la extensión de los espacios o ámbitos del comportamiento en los que vivir sin ser objeto de coacción o interferencia, están aún muy alejadas de la capacidad autoidentificatoria de la libertad de Rawls (p. 188): la capacidad de elección propia de la persona moral no es cualquiera, sino la elección de su modo de vida y esto no lo asegura el rule of law. Tampoco garantiza el rule of law, siempre según Crego, la libertad como independencia (p. 189), pues no afecta a las cuestiones que genuinamente permitirían calificar a un individuo como libre (la definición de su concepción de lo bueno), sino que puede ir referida a asuntos irrelevantes a ese fin.

En definitiva, implícita a los principios de legalidad existe apenas una concepción de la persona como agente racional-deliberante que planifica su comportamiento en función del contenido de las reglas jurídicas. Esta dimensión es una exigencia de la personalidad moral liberal, pero no es suficiente para calificar a un individuo como libre. Un orden social que no respete los principios de legalidad es una afrenta a la libertad, pero un orden que los satisfaga no respeta la libertad por ese simple motivo: el rule of law es un componente necesario de la libertad, pero como tal no tiene valor moral. Por lo tanto, "si se quiere seguir defendiendo el valor moral del rule of law entendido en un sentido formal, es necesario buscar dicho valor en elementos diferentes a la capacidad de acción autoaplicable”, una facultad esta que, además, "está presente en todo orden social basado en directivas explícitas (derecho, planes, directivas gerenciales, mandatos particulares" (p. 191).

A estas conclusiones llega Crego sin incurrir en los errores habituales de algunas de las aportaciones de la primera oleada de críticas a Fuller: Crego (pp. 26-27) caracteriza satisfactoriamente la idea fulleriana de la moral interna del derecho al vincularla con las condiciones necesarias de la empresa de someter al gobierno de reglas el comportamiento humano, evitando así reproducir la asociación de Fuller con alguna variante del iusnaturalismo fruto de algunas equívocas afirmaciones suyas sobre la existencia de "leyes naturales del orden social" (Fuller, 1981, p. 473).

Otros aspectos de la lectura que hace Crego del rule of law en Fuller y de sus principios me parecen más cuestionables. Por ejemplo, creo que Crego no acierta en su distinción entre orden jurídico y control gerencial (managerial direction) o teleocrático (p. 195). La producción de directrices generales, 
prospectivas e inteligibles por un gobernante teleocrático -es decir, la producción de disposiciones que mimetizan los rasgos de las reglas jurídicas- no es relevante, pues la diferencia entre los órdenes teleocráticos y jurídicos no se manifiesta en los rasgos de las "disposiciones" que los componen. Lo relevante es cómo quedan finalmente gobernados en cada uno de esos órdenes los destinatarios de sus disposiciones. En un orden jurídico, por exigencia del principio de congruencia, las pretensiones y conflictos de los individuos se deben adjudicar, es decir, se han de resolver según reglas. Sin embargo, en un orden teleocrático, se deben resolver según convenga al fin social que define al orden a criterio de quien lo gestiona. Ha de ser así también caso por caso, lo que significa que si el castigo a alguien que siguió las directrices generales del gerente interesa a la consecución del fín social, el castigo es la respuesta correcta y su imposición viene exigida por la naturaleza teleocrática del orden. Esto es muy distinto a lo que sucede en el orden jurídico, pese al aparente parecido de los rasgos de las disposiciones respectivas. Así las cosas, la afirmación de que la visión del hombre implícita al rule of law, "es común a cualquier forma de gobierno basada en reglas, incluyendo la managerial direction" (p. 181) quizás tendría que matizarse.

También es cuestionable la concepción de Crego de la moralidad del rule of law, es decir, de la moralidad de los principios de legalidad, que le permite construir sus conclusiones finales. Crego considera que esa moralidad es algo que ha de ser "deducible de la propia naturaleza del derecho", pero parece suponer que es así en el sentido de que se sigue del mismo o que es una emanación o un reflejo del rule of law. Hay una visión alternativa a esta que considero preferible: considerar que la moralidad del derecho es más bien un prius, es decir, algo previo al derecho mismo, de lo que este es expresión. La moralidad del derecho sería lo que lo singulariza como un tipo de orden social específico, no porque esa moralidad sea un efecto que se ve logrado por el derecho, sino porque el derecho es su expresión ${ }^{1}$. Dicho de otro modo, no es que el derecho produzca un bien moral, sino más bien al revés: antes del derecho hay una serie de valores morales, cuya satisfacción exige que las relaciones, la asociación y el gobierno de los individuos se lleven a cabo de un modo determinado y a ese modo es a lo que llamamos orden jurídico. Este es precisamente mi punto de vista: el orden jurídico es expresión de unos valores morales, porque los principios de legalidad, que son constitutivos de la forma del derecho, son la expresión

\footnotetext{
${ }^{1}$ Crego (pp. 29 y 31) parece intuir esta concepción, cuando, con acierto, describe al derecho como una actividad humana de carácter intencional, en el sentido de que responde a un "propósito unificador", que, añade es "más denso de lo que parece".
} 
normativa para el ejercicio del control social de ciertos valores morales: es en ese sentido que el derecho es un fenómeno moral ${ }^{2}$.

Esa comprensión de Fuller cuestiona la lectura habitual que de sus tesis hacen sus críticos y, en particular, cuestiona la distinción entre concepciones formales y sustanciales del rule of law en función de que atiendan al contenido de las normas jurídicas o a los elementos de su forma, la distinción de Craig (1997) que Crego reproduce (p. 27). No creo que la distinción formal/sustancial se aplique correctamente a la concepción de Fuller del rule of law, porque aunque es verdad que para Fuller los principios de legalidad son formales en el sentido de que no están en relación con el contenido de las leyes, lo cierto es que la forma jurídica definida por los principios es, como tal, exigencia de unos valores morales que sí son sustanciales. Desde este punto de vista, la concepción de Fuller del rule of law no es formal, sino sustancial, aunque es verdad que sus efectos sobre el contenido de las normas son muy limitados ${ }^{3}$, pues lo que los principios exigen y lo que satisface los valores constitutivos de los órdenes jurídicos es que normalmente se gobierne mediante reglas y según lo dispuesto en ellas, es decir, atendiendo al contenido que contingentemente adquieran las normas y no de otro modo.

Esta concepción alternativa de Fuller cuestiona la conclusión de Crego (p. 109-111) de que la conexión entre libertad y rule of law es coyuntural y extrínseca, es decir, su tesis de que el rule of law no garantiza el disfrute de una libertad que existe al margen del rule of law mismo y cuya realización “depende completamente de la justicia en sentido sustantivo del sistema jurídico". Desde el punto de vista que planteo, para que el rule of law tenga valor moral no es necesario que realice la libertad en un sentido tan exigente como el supuesto por Crego, es decir, no es necesario -aunque sería deseable- que el contenido del derecho reproduzca las exigencias de un ideal de libertad como el de Rawls: basta con advertir que la forma del derecho reproduce las exigencias de valores morales relativos al modo de ejercicio del control social.

Es más, esa concepción alternativa de Fuller incluso nos invita a concebir el valor moral no como algo bivalente y que, como las reglas, funciona al modo todo o nada, sino algo que puede darse en formas

\footnotetext{
${ }^{2}$ Llegados a este punto y para evitar malentendidos, es necesario insistir en que de aquí no se sigue ninguna moralización del contenido del derecho, pues lo único moralizado es su forma. Y que, en cualquier caso, el valor moral de la forma podría verse superado por el valor moral (negativo) de sus contenidos contingentes. De esto, por cierto, es consciente Crego (p. 227), que recuerda que, según Fuller, el deber de fidelidad al derecho que se seguiría del reconocimiento del valor moral de los presupuestos de su forma, no es un deber incondicional, sino vencible cuando se vea confrontado a un contenido del derecho extremadamente lesivo de la libertad.

${ }^{3}$ Por ejemplo, los principios parecen excluir la posibilidad de un exterminio jurídico (Rundle, 2009).
} 
graduales e imperfectas. Puede ocurrir que algo tenga valor moral o no según lo refiramos a un valor o a otro o que algo sea moralmente valioso en circunstancias típicas y deje de serlo en circunstancias extraordinarias. Una concepción como esta del valor moral evita tener que elegir entre la disposición a reconocer al derecho un valor propio con el riesgo de moralizar el contenido inicuo del derecho -que, según Crego, sería la opción de Fuller-y la negativa a reconocer cualquier valor moral del rule of law, con el riesgo implícito de desechar algo valioso - que sería la de sus críticos- (p. 227). Una concepción matizada del valor moral, alternativa a la de los críticos de Fuller y a la que estos críticos leyeron en Fuller, nos evitaría esa elección entre conservar fruta podrida con la fresca o desechar fruta fresca con la podrida, por decirlo en los expresivos términos de Crego. En su lugar, esa concepción sugiere que hay distintas formas de putrefacción y de frescura y que hay cosas que parecen podridas desde cierto punto de vista, pero que, como ocurre con el Penicillium notatum, pueden tener gran valor desde otro. Probablemente, al valor moral del derecho le ocurre algo parecido. 
BIBLIOGRAFÍA

Aguilera García, Edgar (2017). Jusnaturalismo procedimental, debido proceso penal y epistemología jurídica. México: Tirant lo Blanch.

Allan, Trevor R. S. (2001). Constitutional Justice. Oxford: Oxford University Press.

Cane, Peter [ed.] (2010). The Hart-Fuller Debate in the XXI Century. Oxford: Oxford University Press.

Craig, Paul (1997). "Formal and substantive conceptions of the rule of law: an analytical framework" en Public Law, $\mathrm{n}^{\circ} 3$.

Fuller, Lon (1981). The Principles of Social Order. Durham: Duke University Press.

Nadler, Jennifer (2007). "Hart, Fuller and the Connection between Law and Justice" en Law and Philosophy, vol. 27, pp. 134

Peña Freire, Antonio (2017). Legalidad y orden jurídico. Barcelona: Atelier.

Porciello, Andrea (2016). En los origenes del neoconstitucionalismo. El antipositivismo de Lon. L. Fuller. (Trad. Celia Diéz Fuentes). Lima: Palestra Editores, 2019.

Rundle, Krysten (2009). "The Impossibility of and Exterminatory Legality: Law and the Holocaust" en University of Toronto Law Journal, vol. 59, núm. 1.

Rundle, Krysten (2012). Forms Liberate. Oxford: Hart Publishing.

Waldron, Jeremy (2012). "How Law Protects Dignity” en Cambridge Law Journal, 71 (1).

Witteveen, Willem J. y Burg, Wibren Van der, eds. (1999). Rediscovering Fuller. Essays on Implicit Law and Institutional Design. Ámsterdam: Amsterdam University Press. 